\title{
Iron deficiency anaemia among 6-to-36- month children from northern Angola
}

\author{
Cláudia Fançony ${ }^{1,2^{*}}$, Ânia Soares ${ }^{1}$, João Lavinha ${ }^{3,4}$, Henrique Barros ${ }^{2}$ and Miguel Brito ${ }^{1,5}$
}

\begin{abstract}
Background: Angola is one of the southern African countries with the highest prevalence of anaemia. Identifying anaemia determinants is an important step for the design of evidence-based control strategies. In this study, we aim at documenting the factors associated with Iron Deficiency Anaemia (IDA) in 948 children recruited at the Health Research Center of Angola study area during 2015.

Methods: Data on demographic, socio-economic and parental practices regarding water, sanitation, hygiene, malaria infection and infant and young child feeding were collected, as well as parasitological, biochemical and molecular data. Total and age-stratified multivariate multinomial regression models were fitted to estimate the magnitude of associations between anaemia and its determinants.
\end{abstract}

Results: Anaemia was found in $44.4 \%$ of children, of which $46.0 \%$ had IDA. Overall, regression models associated IDA with age, gender and inflammation and non-IDA with age, zinc deficiency and overload, P. falciparum infection, sickle cell trait/anaemia. Among 6-to-23-month-old children IDA was associated with continued breastfeeding and among 24-to-36-month-old children IDA was associated with stunting. Furthermore, zinc deficiency was associated with non-IDA among both age groups children. Inflammation was associated with IDA and non-IDA in either 6-to23 and 24-to-36 months old children.

Conclusion: The main variables associated with IDA and non-IDA within this geographic setting were commonly reported in Africa, but not specifically associated with anaemia. Additionally, the associations of anaemia with inflammation, zinc deficiency and infections could be suggesting the occurrence of nutritional immunity and should be further investigated. In age groups, zinc overload was observed to protect under 6 months children from Non-IDA, while continued breastfeeding was associated with increased IDA prevalence in 6-to-23 months children, and stunting was suggested to increase the odds of IDA in 24-to-36 month children. This site-specific aetiology profile provides an essential first set of evidences able to inform the planification of preventive and corrective actions/programs. Nevertheless, regional and country representative data is needed.

Keywords: Iron deficiency anaemia, Aetiologies, Preschool children, Northern Angola

\section{Background}

Several studies have summarized the worldwide prevalence of anaemia, reported to be $30 \%$ in $1985,33.3 \%$ in $1990,32.9 \%$ in 2010 and $27.0 \%$ in 2013 [1-8]. Kassebaum et al reported that globally the prevalence dropped

\footnotetext{
* Correspondence: cisa.cfv@gmail.com

${ }^{1}$ Health Research Center of Angola (CISA, translated), Caxito, Angola ${ }^{2}$ Instituto de Saúde Pública da Universidade do Porto, Porto, Portugal Full list of author information is available at the end of the article
}

between 1990 and 2010/2013, as well as the number of countries with prevalence higher than 50\% (from 20 to 4 countries) [1, 4, 9, 10]. In Angola, the southern African country with the highest prevalence in 1990, a similar tendency of decreasing prevalence was reported (from 50 to $60 \%$ in 1990 to $40-50 \%$ in 2013 for all ages) [4]. In 2010 , the regional prevalence of anaemia in children was reported to be $21.6 \%$ in the south and $57 \%$ in the north of the country. A national multiple indicators survey,

C The Author(s). 2020 Open Access This article is licensed under a Creative Commons Attribution 4.0 International License, which permits use, sharing, adaptation, distribution and reproduction in any medium or format, as long as you give appropriate credit to the original author(s) and the source, provide a link to the Creative Commons licence, and indicate if changes were made. The images or other third party material in this article are included in the article's Creative Commons licence, unless indicated otherwise in a credit line to the material. If material is not included in the article's Creative Commons licence and your intended use is not permitted by statutory regulation or exceeds the permitted use, you will need to obtain permission directly from the copyright holder. To view a copy of this licence, visit http://creativecommons.org/licenses/by/4.0/. The Creative Commons Public Domain Dedication waiver (http://creativecommons.org/publicdomain/zero/1.0/) applies to the data made available in this article, unless otherwise stated in a credit line to the data. 
conducted between 2015 and 2016, reported that $65 \%$ of 6 to 59 months were anaemic, and the prevalence was higher in 6-to- 11 months children $83 \%$ in $6-8$ months and $82 \%$ in $9-11$ months children) and that higher severity occurred in 12-17 months children [11-13].

Despite being the single most important cause of anaemia and anaemia-related disability, the contribution of iron deficiency showed a modest decrease (from 66.2 to $62.6 \%$ between 1990 and 2013) [4]. Besides iron deficiency, hookworm, sickle cell disorders, thalassaemias, schistosomiasis, and malaria were also important causes, although showing substantial variability with age, gender, and geography [1, 4]. For instance, the most relevant cause-specific prevalence of anaemia in Western and Central sub-Saharan Africa were reported to be malaria and haemoglobinopathies, which collectively explained $80 \%$ of anaemia cases [4]. In Angola, anaemia has been associated with undernutrition (responsible for 13\% of the anaemia cases), but also with infections, namely by Hymenolepis nana, Plasmodium falciparum and Schistosoma haematobium $[13,14]$. The last 2 parasites were reported to be responsible for 16 and $10 \%$ of the anaemia cases in children living in the Dande municipality, respectively $[13,14]$. According to the few existing studies regarding the aetiologic profile of anaemia in Angola, undernutrition and infections are important contributors to the total burden in the country, although micronutrient deficiencies have not been fully explored [13, 14]. Associations between nutritional and infectious aetiologies should be further investigated considering their relevance and that no published data is currently available for this setting. For instance, nutritional anaemias are reported to be directly linked to micronutrient deficiencies, which in turn can be associated with underlying, intermediate and/or immediate causes of malnutrition $[9,15]$. However, infections can also cause anaemia indirectly through micronutrient deficiencies, despite that other mechanisms may cause non-nutritionally related anaemias (such as malabsorption, chronic blood loss, anorexia, inflammation or haemolysis) $[15,16]$.

From a public health point of view, a context-specific aetiologic profile should be determined in order to design the appropriate preventive, control or treatment strategies [17]. For instance, the coexistence of iron deficiency and malaria may highlight the paradox for anaemia control, as iron supplementation was suggested to increase malaria risk, and the infection was recommended to be screened and treated before supplementation [18, 19]. Additionally, the attributable weight of hereditary causes, such as sickle cell anaemia and Glucose-6-phosphate dehydrogenase deficiency, should also be investigated, as they may in turn be directly associated with the occurrence of total anaemia, or influence the occurrence of other causes mentioned above $[15,20,21]$.
In the present study, considering that iron deficiency anaemia (IDA) is the endpoint for several direct and indirect causal pathways, and that it is reported to play a major role on the total burden of anaemia, we aim at documenting key basic, intermediate, and immediate nutritional determinants of IDA, accounting also for the contribution of hereditary haemolytic factors.

\section{Methods}

\section{Study design and sampling}

The sampling strategy, chosen for this observational cross-sectional study, was a non-probabilistic (convenient) sampling. First, we identified administratively and geographically isolated hamlets with functional health posts (i.e., providing daily primary care), in turn located within the CISA's HDSS study area. Then, all under 3 years old children resident in those hamlets were listed and invited to participate, using a census approach. The criterion to define eligible hamlets was based in the higher facilities in mobilizing the population and logistical advantages associated with health posts, while the census approach was adopted because variations in the density of eligible children estimated by CISA's HDSS database, were expected and the real density in each cluster was needed.

\section{Study site and population}

Resulting from this sampling strategy, seven hamlets with functional health posts were selected from the CISA's Health and Demographic Surveillance System (HDSS) study area [22]. CISA's $4700 \mathrm{~km} 2$ study area, comprehend mostly 3 communes from the Dande municipality in the Bengo Province, where the demographic and economic aspects of their 15,579 households and 59,635 residents (registered initially) are being followed since 2009 and where several studies have been conducted [13, 14, 22-28]. In average, each household of that area have 3.8 inhabitants (4.2 in urban and 3 in rural areas), that live frequently in houses made mainly by adobe walls, iron sheets roofs, without kitchen (near $70 \%$ of the houses) and without latrines (or having to chare them) [23]. Drinking water was reported to be obtained mainly from an unimproved source, namely from rivers (48\%), unprotected dug well $(10 \%)$ and/or lakes and irrigation channels (3\%) [23]. Additionally, bed-net coverage $(25.1 \%)$ and history of previous treatment for $S$. haematobium and Geohelminth infections in preschool children were reported to be low in 2010 (3.5 and 15.9\%, respectively). Contrasting with the prevalence of being infected with at least one or 2 geohelminth infection was 22.6 and $3.8 \%$, respectively, at the same period $[13,14]$.

For this study, all under-3-year-old children and their mothers/caregivers, resident in the selected hamlets were considered eligible, being listed and invited to participate (using a census approach). 
After explaining the study's objectives, and obtaining verbal acceptance to participate, the field technician delivered a "participant information form" and a stool container to eligible families and instructed them to be present at the health center for evaluation the following day. At the end of the census approach, 1106 households were considered eligible and were invited to participate. Of those, 830 primary caregivers (mainly the children's mothers) attended to the evaluation day at the health centers and signed an informed consent. In total, 948 children were evaluated. Approximately half of the children with evaluable data were aged between 6 and 23 months: $517 / 943(54.9 \%)$ with a similar proportion of boys $(50.6 \%, 479 / 946)$ and girls $(49.4 \%, 467 / 946)$. Additionally, one third of the children lived in a household with 4 or 5 more residents $(35.3 \%, 335 / 948)$, and close to half lived with another under 5-years old child $(48.5 \%, 330 / 680)$.

\section{Training}

For this study, 6 field workers and 2 nurse technicians (nurse's aide or assistant) were selected and trained. The training course comprehended theoretical lessons on: 1) introduction to research questions, 2) study goals and design, 3) basic concepts regarding the diseases studied, 4) mobilization techniques, 5) methodologies for data collection (specific structured questionnaire interviews, anthropometric evaluations, recognition of signs and symptoms of micronutrient deficiency and temperature measurement). Nurse technicians undergone an additional 3-day training on: 1) best practices for drug administration to young children and 2) domiciliary treatment and 3) support to physician in hospital-based consultations.

\section{Sample and data collection}

A standardized questionnaire was administered to caregivers. Data was collected regarding demographics (age, gender, household size and number of under 5 children household residents) socio-economic (monthly income, daily expenditure with food and water, ownership of latrine, crop field and bednet and activities of hunting or breeding animals) and parental practices (water sanitation and hygiene (WASH), malaria and Infant and Young Child Feeding (IYCF)) [29, 30]. The monthly income, daily expenditure with food and water were analysed based on the cut-offs of 15,000 AKZ (approx. 40 EUR), 1000 AKZ (approx. 3 EUR) and 200 AKZ (approx. 0.6 EUR), respectively. Furthermore, the proportion of children in exclusive breastfeeding (regarding children under 6 months who were reported to have received only breast milk), in continued breastfeeding (children over 5 months who were both breastfed and complementary fed), that have achieved the individual Minimum Dietary Diversity (MDD, to those older than 5 months who consumed 4 or more foods from the groups: 1) grains, roots and tubers, 2) legumes and nuts, 3) dairy products, 4) flesh foods, 5) eggs, 6) vitamin Arich fruits and vegetables, and 7) other fruits and vegetables), who consumed haeme-iron (animal based foods, mainly organs and meat, poultry, eggs and fish) and non-haeme iron rich foods (plant-based foods, mainly legumes and dark green leafy vegetables), were classified as previously described, using $24 \mathrm{~h}$ recall data [30, 31].

Weight, measured in electronic or platform scales, height (measured in standardized infantometer or stadiometers) and oedema, were collected and used to calculate the anthropometric indices to classify malnutrition (either in children's and their caregivers), following WHO guidelines [32]. Mid-Upper Arm Circumference (MUAC) was used to classify acute malnutrition and to refer children to the emergency unit of Bengo's General Hospital. Peripheral blood was collected on site according to WHO guidelines to good phlebotomy practice [33]. The blood samples for iron, zinc and C-reactive protein (CRP) determination were collected into Micro tubes $1.1 \mathrm{ml} \mathrm{Z-Gel}{ }^{\bullet}$ (Sarstedt, Nümbrecht, Germain), then centrifuged to separate serum, which in turn was stored at $-20^{\circ} \mathrm{C}$ until processing. Blood samples for molecular analysis were collected on filter paper, air dried and stored until processing. Stool and urine samples were obtained on or around the evaluation day, with exception of some younger children incapable to verbalize urge to urinate, in which a paediatric urine collection bag was applied. Formalin (10\%) was added to stool samples, and along with urine samples, were stored in a thermal box with coolers for transportation to the lab (no more than $4 \mathrm{~h}$ ).

\section{Laboratorial analyses}

Parasitological analysis comprised the diagnosis of $P$. falciparum and $P$. vivax malaria, performed using a rapid diagnostic test (SD BIOLINE Malaria Ag P.f/P.v ${ }^{\circ}$, Standard Diagnostics, Inc., Republic of Korea) according to the manufacturer guidelines. Diagnosis of intestinal parasites were performed using Kato-Katz technique and Parasitrap ${ }^{\circ}$ kits (Biosepar, Germany) and urogenital schistosomiasis was diagnosed by urine filtration, using Whatman ${ }^{\circ}$ Nuclepore $^{\mathrm{Tm}}$ membranes (diam. $25 \mathrm{~mm}$, pore size $12 \mu \mathrm{m}$, polycarbonate, Merck, Germany) [34-36]. Biochemical analysis included determining blood levels of haemoglobin using an Hemocue ${ }^{\circ} \mathrm{Hb} 301$ System (Angelholm, Sweden), CRP serum levels, ferritin and zinc, using an automated autoanalizer (BT1500, Biotecnica Instruments S.p.A, Rome, Italy) and CRP turbidimetric latex ${ }^{\circ}$, Ferritin ${ }^{\circ}$ and Zinc ${ }^{\circ}$ kits (Quimica Clínica Aplicada S.A., Tarragona, Spain). Molecular analyses comprehended DNA extraction using InstaGene ${ }^{\mathrm{Tw}}$ Matrix (Bio-Rad laboratories, Inc. United States of América), 
screening for sickle cell anaemia and sickle cell trait (by PCR-RFLP), and G6PD deficiency (by rtPCR) [37, 38].

Children were considered anaemic if haemoglobin $(\mathrm{Hb})$ levels were below $11.0 \mathrm{~g} / \mathrm{dL}$ with the following stratification: mild anaemia if $\mathrm{Hb}$ was between 10.0 and $10.9 \mathrm{~g} / \mathrm{dL}$, moderate anaemia if $\mathrm{Hb}$ was between 7.0 and $9.9 \mathrm{~g} / \mathrm{dL}$ and severe anaemia if $\mathrm{Hb}$ was lower than $7.0 \mathrm{~g} / \mathrm{dL}[5,39,40]$. Iron-deficiency was considered to be present if serum levels of ferritin were below $12 \mu \mathrm{g} / \mathrm{L}$ in the absence of inflammation or below $30 \mu \mathrm{g} / \mathrm{L}$ if inflammation (serum CRP levels higher than $5 \mathrm{mg} / \mathrm{L}$ ) was present [41]. IDA was considered when $\mathrm{Hb}$ level was below $11.0 \mathrm{~g} / \mathrm{dL}$ and ferritin deficiency was also observed. Pathological zinc levels were considered whenever, serum levels were bellow $70.0 \mu \mathrm{g} / \mathrm{dL}$ (Zinc deficiency) or above $150.0 \mu \mathrm{g} / \mathrm{dL}$ (Zinc overload) [42].

Prevalence of the studied parasites was determined as the proportion between all infected children and all children delivering the correspondent sample. Children were considered to have diarrhoea if caregivers reported that the children had at least one episode of 3 or more aqueous dejections per day in the last 2 weeks. Z- scores of weight-forage (WAZ), height-for-age (HAZ) and weight-for-height (WHZ) were determined using WHO Anthro software (version 3.2.2) for children and body mass index (BMI) was calculated and used to classify undernutrition in their mothers (considered to be eutrophic if BMI 18.50-24.99 $\mathrm{kg} / \mathrm{m}^{2}$, undernourished if $\mathrm{BMI}<18.50 \mathrm{~kg} / \mathrm{m}^{2}$ and overnourished if $\mathrm{BMI}>25 \mathrm{~kg} / \mathrm{m}^{2}$ [43].

\section{Statistics}

In this study, 95\% confidence intervals (CI95) were estimated for the prevalence's. Crude multinomial models were fitted, each with a single independent variable and taking children without anaemia as the reference category of the dependent variable (vs. IDA and non-IDA anaemia). Variables that in those models were significantly associated with any type of anaemia, considering a significance level of $10 \%(p<0.10)$, were then included as independent variables in a multivariate multinomial model. For those models, the manual stepwise method was used to retain only the variables with an association with anaemia, at a significance level of $5 \%(p<0.05)$ in the final model. Models considering all children and stratified by age groups (children under 6 months, between 6 and 23 months and between 24 and 36 months) were fitted. Nagelkerke R square was used to evaluate the goodness of fit of the models.

\section{Results}

Nutritional status of children and their feeding practices

The prevalence of moderate to severe undernutrition was as follows: $9.9 \%$ wasting, $26.7 \%$ stunting and $20.3 \%$ underweight. Anaemia was present in $44.4 \%$ of children, $46.0 \%$ of which were diagnosed with IDA. Serum levels of ferritin, corrected for inflammation, showed $38.1 \%$ of additional iron deficient children.

Regarding the feeding practices, we found that $49.3 \%$ of the under 6 months children reported to be exclusively breastfeed in the previous $24 \mathrm{~h}$. Also, $52.5 \%$ of children with 6 or more months were breastfed and complementary fed. The Minimum Dietary Diversity (MDD) for continued breastfed children was lower $(11.4 \%, 72 / 633)$ than children being only complementary fed $(14.2 \%, 93 / 633)$. Many of the children that did not meet the MDD were found to consume mainly foods from 2 or 3 food groups (36.2\% (203/561) and 56.7\% (318/561), respectively). Haeme-iron and non-haeme iron rich foods were reported to have been consumed by 75.8 and $35.3 \%$ of the children aging 6 or more months of age (Table 1 ).

We observed that $39.4 \%(186 / 472)$ of the caregivers reported to spend more than $200 \mathrm{AKZ}$ per day in water, while $33.5 \%$ (292/871) reported to spend more than 1000 AKZ per day in food. Also, 40.1\% (371/927) reported to being subsistence farmers and 26.6\% (246/924) reported breeding or hunting animals (Table 1).

\section{Infectious state of children and mother-to-children infection preventive practices}

Within the children with evaluable data, $45.3 \%$ had CRP levels consistent the occurrence of inflammatory processes. Of those, 3.3\% had malaria (considered here as malarial inflammation) and $42.0 \%$ were considered nonmalarial inflammation. Furthermore, the prevalence of $P$. falciparum, A. lumbricoides, G. lamblia and S. haematobium was 5.2, 3.8, 7.5, 6.3 and $15.2 \%$, respectively. Despite being less prevalent, $T$. trichiura $(0.5 \%, 4 / 787)$, E. histolytica $(0.3 \%, 2 / 787), S$. mansoni $(0.1 \%, 1 / 787), H$. nana $(0.8 \%, 6 / 787)$ and $S$. stercoralis $(0.5 \%, 4 / 787)$ were also observed. Diarrhoea in the 2 weeks prior to evaluation was reported in $41.2 \%$ of the children. Eggs from hookworms were not observed, either by Kato-Katz or Parasitrap.

There were bednets in 50.6\% (470/929) of the households and $42.8 \%$ (391/913) of the children had slept under the bednet in the previous night. Furthermore, $73.5 \%(685 / 932)$ of the caregivers reported to treat the drinking water, which $50.4 \%(467 / 927)$ was obtained from natural sources. The water used for bathing was also reported to be mainly obtained from unimproved sources (63.1\%, 502/796). Despite that, 74.4\% (694/933) of the caregivers reported to have latrine, 35.0\% (327/ 935) reported to deposit the stool in open sky when outside, while the majority reported to deposit in latrines or bury the stool. We also observed that $70.5 \%$ (589/835) of children were wearing shoes at the evaluation moment.

\section{Genetic features of children}

Regarding genotyping, we observed that 42.5\% (195/459) of the females had at least one G6PD polymorphism (B/ 
Table 1 Characterisation of study children: demographics, nutritional status, Infant and Young Child Feeding practices, infections and infection preventive practices and genetic features

\begin{tabular}{|c|c|c|c|c|}
\hline Variables & Categories & $\mathrm{n}$ & $\mathrm{N}$ & Estimated proportion $(95 \% \mathrm{Cl})$ \\
\hline \multicolumn{5}{|l|}{ Demographic characteristic of children } \\
\hline \multirow[t]{3}{*}{ Age (in months) } & $<6$ months & 155 & 948 & $16.4(14.1-18.8)$ \\
\hline & 6-23 months & 520 & 948 & $54.9(51.7-58)$ \\
\hline & 24-36 months & 273 & 948 & $28.8(26-31.8)$ \\
\hline \multirow[t]{2}{*}{ Gender } & Female & 459 & 948 & $48.4(45.2-51.6)$ \\
\hline & Male & 489 & 948 & $51.6(48.4-54.8)$ \\
\hline \multicolumn{5}{|l|}{ Nutritional status and feeding practices } \\
\hline \multirow[t]{3}{*}{ Anaemia } & No & 527 & 912 & $57.8(54.6-61)$ \\
\hline & IDA & 177 & 912 & $19.4(17-22.1)$ \\
\hline & Non-IDA & 208 & 912 & $22.8(20.2-25.6)$ \\
\hline Zinc deficiency & Yes & 58 & 687 & $8.4(6.6-10.8)$ \\
\hline Zinc overload & Yes & 165 & 794 & $20.8(18.1-23.7)$ \\
\hline Wasting & Moderate to severe & 93 & 942 & $9.9(8.1-11.9)$ \\
\hline Stunting & Moderate to severe & 252 & 943 & $26.7(24-29.6)$ \\
\hline Underweight & Moderate to severe & 191 & 943 & $20.3(17.8-22.9)$ \\
\hline Exclusive breastfeeding (< 6 months) & $Y_{e s}^{a}$ & 74 & 150 & $49.3(41.4-57.3)$ \\
\hline Continued breastfeeding (6 to 36 months) & $Y_{e s}^{a}$ & 413 & 786 & $52.5(49-56)$ \\
\hline Minimum Dietary Diversity ( 6 to 36 months) & $Y_{e s}^{a}$ & 165 & 726 & $22.7(19.8-25.9)$ \\
\hline Non-haeme Iron rich foods (6 to 36 months) & $Y_{e s}{ }^{a}$ & 256 & 726 & $35.3(31.9-38.8)$ \\
\hline Haeme Iron rich foods (6 to 36 months) & $\mathrm{Yes}^{\mathrm{a}}$ & 550 & 726 & $75.8(72.5-78.7)$ \\
\hline \multirow[t]{3}{*}{ Feeding frequency (6 to 36 months) } & $0-1$ times & 73 & 703 & $10.4(8.3-12.9)$ \\
\hline & $2-3$ times & 389 & 703 & $55.3(51.6-59)$ \\
\hline & $>=4$ times & 241 & 703 & $34.3(30.9-37.9)$ \\
\hline \multicolumn{5}{|l|}{ Infections and infection preventive practices } \\
\hline P. falciparum & Yes & 49 & 946 & $5.2(3.9-6.8)$ \\
\hline At least one intestinal/urogenital parasite & Yes & 127 & 833 & $15.2(13-17.8)$ \\
\hline A. Lumbricoides & Yes & 30 & 787 & $3.8(2.7-5.4)$ \\
\hline G. lamblia & Yes & 59 & 783 & $7.5(5.9-9.6)$ \\
\hline S. haematobium & Yes & 36 & 570 & $6.3(4.6-8.6)$ \\
\hline Diarrhoea in the last 2 weeks & $Y_{e s}^{a}$ & 386 & 938 & $41.2(38-44.3)$ \\
\hline \multirow[t]{3}{*}{ Inflammation (CRP) } & No & 465 & 850 & $54.7(51.3-58)$ \\
\hline & Malarial inflammation & 28 & 850 & $3.3(2.3-4.7)$ \\
\hline & Non-malarial inflammation & 357 & 850 & $42(38.7-45.3)$ \\
\hline Sleeping under the bednet in the previous night & Yes & 391 & 913 & $42.8(39.7-46.1)$ \\
\hline Treated drinking water & Yes & 685 & 932 & $73.5(70.6-76.2)$ \\
\hline \multirow[t]{2}{*}{ Main source of drinking water } & Unsafe (river, lagoon) & 467 & 927 & $50.4(47.2-53.6)$ \\
\hline & Safe (piped, fountain) & 460 & 927 & $49.6(46.4-52.8)$ \\
\hline \multirow[t]{2}{*}{ Main source of water for bath } & Unsafe (river, lagoon) & 502 & 796 & $63.1(59.7-66.3)$ \\
\hline & Safe (piped, fountain) & 294 & 796 & $36.9(33.7-40.3)$ \\
\hline \multirow[t]{2}{*}{ Place for faecal disposal } & Unsafe (open sky) & 327 & 935 & $35(32-38.1)$ \\
\hline & Safe (latrine or buried) & 608 & 935 & $65(61.9-68)$ \\
\hline Wearing shoes at evaluation & Yes & 589 & 835 & $70.5(67.4-73.5)$ \\
\hline
\end{tabular}


Table 1 Characterisation of study children: demographics, nutritional status, Infant and Young Child Feeding practices, infections and infection preventive practices and genetic features (Continued)

\begin{tabular}{|c|c|c|c|c|}
\hline Variables & Categories & $n$ & $\mathrm{~N}$ & Estimated proportion ( $95 \% \mathrm{Cl})$ \\
\hline \multicolumn{5}{|l|}{ Genetic features } \\
\hline \multirow[t]{2}{*}{ G6PD genotype of females } & $B / B, A / A, B / A$ & 264 & 459 & $57.5(53-62)$ \\
\hline & $B / A-, A / A-, A-/ A-$ & 195 & 459 & $42.5(38-47)$ \\
\hline \multirow[t]{2}{*}{ G6PD genotype of males } & $B, A$ & 271 & 479 & $56.6(52.1-60.9)$ \\
\hline & A- & 208 & 479 & $43.4(39.1-47.9)$ \\
\hline \multirow[t]{3}{*}{ Sickle cell (HBB genotype) } & $\mathrm{AA}$ & 629 & 848 & $74.2(71.1-77)$ \\
\hline & AS & 203 & 848 & $23.9(21.2-26.9)$ \\
\hline & SS & 16 & 848 & $1.9(1.2-3)$ \\
\hline
\end{tabular}

${ }^{\mathrm{a}}$ Definition is described in Methods

A- (29.6\%), A/A- (8.3\%) and A-/A- (4.6\%)), while a similar prevalence occurred in males,43.4\% (208/479). In addition, $23.9 \%(203 / 848)$ of the children were found to have the sickle cell trait and 1.9\% (16/848) were homozygous for sick cell anaemia (Table 1).

\section{Characteristics of caregivers}

Caregivers were mainly young adults with ages between 20 and 39 years, followed by adolescents (under 20 years old) and older adults (above 40 years old). The majority were the children's mothers, married or living with their partner and reporting to have attended school. Additionally, the mothers' anthropometric measures according to their Body Mass Index (BMI) revealed that $59.7 \%$ had an adequate nutritional status, while $34.1 \%$ were overweight and $6.2 \%$ underweight (Table 2).

\section{Factors associated with IDA and non-IDA}

In crude multinomial models, and compared with children without anaemia, the occurrence of IDA was associated with age (OR:11.1, 95\%CI: 4.42-27.96 for $6-23$ months children and OR:3.5, CI: $1.31-9.20$ for $24-36$ months), gender (OR:1.9, CI: 1.33-2.69 for males), having intestinal/ urogenital parasite (where children with at least one studied parasite appearing to be less likely to have IDA than children without any parasite, OR:0.5, CI: 0.28-0.90), and having inflammation (OR:4.7, CI: 1.6513.43 for inflammation plus malaria infection and OR: 2.4, CI: $1.67-3.44$ for inflammation without malaria infection). The same models suggested that Non-IDA was associated with the school level of caretakers (OR:1.8, CI: $1.02-3.21$ for those achieving the primary level, when compared to those without school frequency), source of drinking and bath water (OR:0.7, CI: 0.48-0.91 and OR: 0.6, CI: 0.44-0.93, respectively, for artificial/improved sources), zinc levels with children with zinc deficiency having higher odds of having Non-IDA than children with normal values (OR:2.8, CI: 1.56-5.19), and children with zinc overload being less likely to have Non-IDA than children with normal levels (OR:0.6, CI: 0.380.95)), malarial inflammation (OR:4.6, CI: 1.79-11.83), $P$. falciparum infection (OR: 3.2, CI: 1.63-6.21), and both sickle cell trait and sickle cell anaemia (OR:1.6, CI: 1.052.27 and OR:17.7, CI: 3.91-80.22, respectively).

Furthermore, crude multinomial age-stratified analysis showed that among children under 6 months,

non-IDA was associated with age (OR:1.3, CI:1.0671.591 ) and with having zinc overload (where children with zinc overload had significantly less Non-IDA than under 6 months children with normal zinc levels (OR:0.3, CI:0.13$0.79)$ ). Unfortunately, numeric problems didn't allow to investigate associations with IDA. Furthermore, children aged between 6-to-23 months were more likely to be diagnosed with IDA if they were males (OR:2.3, CI:1.48-3.46), being continued breastfeeding (OR:1.7, CI:1.05-2.82) and if they had inflammation without malaria (OR:2.3, CI:1.46-3.50). These associations weren't observed to occur regarding the diagnosis of Non-IDA. Nevertheless, in this age group, the diagnosis of Non-IDA was more likely to occur among children living in households with one additional children under 5 (OR:2.4, CI:1.15-4.82, comparatively to none), $P$. falciparum infection (OR:5.4, CI:1.98-14.94), inflammation with malaria (OR:8.3, CI:2.16-31.99) and/or having sickle cell anaemia (OR:20.2, CI:2.44-167.49, comparatively to having a normal genotype or having the sickle cell trait), associations that weren't observed for children in the same age group with IDA. In older children (aging between 24 and 36 months) the occurrence of IDA appeared to be associated with the number of residents in the same household (OR: 0.4, CI:0.15-0.83, for living with more than 5 residents), children being moderate-to-severely stunted (OR: 2.5, CI:1.14-5.50) and having inflammation (OR:4.3, CI: 1.69-11.02). Similarly, to the previous age group, children aging between 24 and 36 months that had zinc deficiency were also more likely to have Non-IDA than children with normal zinc levels (OR:3.1, CI:1.31-7.52),

When all variables with significant associations with either IDA or Non-IDA were added to a multivariate multinomial regression model, only age, gender and 
Table 2 Characterisation of households and caregivers of studied children

\begin{tabular}{|c|c|c|c|c|}
\hline Variables & Categories & $\mathrm{n}$ & $\mathrm{N}$ & Estimated proportion (95\% Cl) \\
\hline \multicolumn{5}{|l|}{ Household characteristics } \\
\hline \multirow[t]{2}{*}{ Estimated monthly income (AKZ) } & $<15,000$ & 356 & 602 & $59.1(55.2-63)$ \\
\hline & $\geq 15,000$ & 246 & 602 & $40.9(37-44.8)$ \\
\hline Daily food expenditure (AKZ) & $<1000$ & 579 & 871 & $66.5(63.3-69.5)$ \\
\hline Median = 1000.0; Mean = 1361.2; SD = 2486.5 & $\geq 1000$ & 292 & 871 & $33.5(30.5-36.7)$ \\
\hline Daily water expenditure (AKZ) & $<200$ & 286 & 472 & $60.6(56.1-64.9)$ \\
\hline Median = 200.0; Mean = 368.7; SD = 1095.8 & $\geq 200$ & 186 & 472 & $39.4(35.1-43.9)$ \\
\hline Latrine ownership & Yes & 694 & 933 & $74.4(71.5-77.1)$ \\
\hline Bednet ownership & Yes & 470 & 929 & $50.6(47.4-53.8)$ \\
\hline Ownership of land for agriculture & Yes & 372 & 927 & $40.1(37-43.3)$ \\
\hline Breeding or hunting animals & Yes & 246 & 924 & $26.6(23.9-29.6)$ \\
\hline Number of residents & $<=3$ & 137 & 948 & $14.5(12.4-16.8)$ \\
\hline \multirow[t]{3}{*}{ Median =6.0; Mean = 5.9; SD = 2.5} & $4-5$ & 335 & 948 & $35.3(32.4-38.4)$ \\
\hline & $6-7$ & 262 & 948 & $27.6(24.9-30.6)$ \\
\hline & $>=8$ & 214 & 948 & $22.6(20-25.3)$ \\
\hline Number of children under 5 years old & None & 170 & 680 & $25(21.9-28.4)$ \\
\hline \multirow[t]{2}{*}{ Median = 1.0; Mean = 1.2; SD = 1.2} & 1 & 330 & 680 & $48.5(44.8-52.3)$ \\
\hline & $>=2$ & 180 & 680 & $26.5(23.3-29.9)$ \\
\hline \multicolumn{5}{|l|}{ Characteristics of the caregivers } \\
\hline Age & $<20$ years & 150 & 861 & $17.4(15-20.1)$ \\
\hline \multirow[t]{2}{*}{ Median $=27.0 ;$ Mean $=27.6 ; \mathrm{SD}=8.5$} & 20-39 years & 643 & 861 & $74.7(71.7-77.5)$ \\
\hline & $>40$ years & 68 & 861 & $7.9(6.3-9.9)$ \\
\hline \multirow[t]{2}{*}{ Gender } & Male & 35 & 828 & $4.2(3.1-5.8)$ \\
\hline & Female & 793 & 828 & $95.8(94.2-96.9)$ \\
\hline \multirow[t]{2}{*}{ Marital status } & Married or living with partner & 660 & 817 & $80.8(77.9-83.3)$ \\
\hline & Single, divorced or widow & 157 & 817 & $19.2(16.7-22.1)$ \\
\hline School frequency & Yes & 701 & 804 & $87.2(84.7-89.3)$ \\
\hline \multirow[t]{3}{*}{ Education level achieved } & Primary level & 238 & 655 & $36.3(32.7-40.1)$ \\
\hline & Basic level & 330 & 655 & $50.4(46.6-54.2)$ \\
\hline & High school to university & 87 & 655 & $13.3(10.9-16.1)$ \\
\hline $\begin{array}{l}\text { Number of children under } 5 \text { years } \\
\text { old in the household }\end{array}$ & $<=2$ & 344 & 813 & $42.3(39-45.7)$ \\
\hline \multirow[t]{2}{*}{ Median $=3.0 ;$ Mean $=3.3 ; \mathrm{SD}=2.0$} & $3-4$ & 265 & 813 & $32.6(29.5-35.9)$ \\
\hline & $>=5$ & 204 & 813 & $25.1(22.2-28.2)$ \\
\hline \multirow[t]{3}{*}{ Nutritional status of mothers ${ }^{a}$} & Eutrophic (BMI 18.50-24.99kg/m²) & 478 & 801 & $59.7(56.2-63)$ \\
\hline & Underweight $\left(\mathrm{BMI}<18.50 \mathrm{~kg} / \mathrm{m}^{2}\right)$ & 50 & 801 & $6.2(4.8-8.1)$ \\
\hline & Overweight and obese (BMl > $\left.25 \mathrm{~kg} / \mathrm{m}^{2}\right)$ & 273 & 801 & $34.1(30.9-37.4)$ \\
\hline
\end{tabular}

${ }^{a}$ Only non-pregnant mothers were included

inflammation sustained the statistical significance association with IDA, suggesting that children 6-to-23 months had higher probability of having IDA than under 6 months children, similarly for males comparatively to females and non-malarial inflammation comparatively to children with no inflammation, while $P$. falciparum, sickle cell trait and sickle cell anaemia sustained their significantly association with Non-IDA, with age becoming also significantly associated (Table 3).

In the age-stratified adjusted models we found that Non-IDA in under 6-month children was associated with age and zinc overload. Furthermore, among 6-to23 months children, the occurrence of IDA sustained its association with gender, being continued breastfeed and 
Table 3 Multinomial multivariate regression models for IDA and non-IDA

\begin{tabular}{|c|c|c|c|c|c|c|}
\hline \multirow[t]{2}{*}{ Independent variables } & & \multirow[t]{2}{*}{ Non anemic } & IDA & \multirow[t]{2}{*}{$p$} & Non-IDA & \multirow[t]{2}{*}{$p$} \\
\hline & & & OR (IC95\%) & & OR (IC95\%) & \\
\hline \multicolumn{7}{|l|}{ Total population (1) } \\
\hline \multirow[t]{3}{*}{ Age } & $<6$ months & 1 & Ref & & Ref & \\
\hline & $6-23$ months & & $7.4(2.87,19.11)$ & $<0.001$ & $0.7(0.43,1.15)$ & 0.166 \\
\hline & $24-36$ months & & $2.0(0.73,5.53)$ & 0.180 & $0.5(0.27,0.80)$ & 0.006 \\
\hline \multirow[t]{2}{*}{ Children's gender } & Female & 1 & Ref & & Ref & \\
\hline & Male & & $2.0(1.32,2.91)$ & 0.001 & $1.3(0.87,1.81)$ & 0.216 \\
\hline \multirow[t]{3}{*}{ Zinc } & Normal & 1 & Ref & & Ref & \\
\hline & Deficiency & & $1.6(0.67,3.61)$ & 0.306 & $3.2(1.64,6.25)$ & 0.001 \\
\hline & Overload & & $0.8(0.47,1.26)$ & 0.300 & $0.6(0.36,0.96)$ & 0.033 \\
\hline \multirow[t]{2}{*}{ P. falciparum } & No & 1 & Ref & & Ref & \\
\hline & Yes & & $1.3(0.26,6.81)$ & 0.733 & $3.1(1.05,9.42)$ & 0.041 \\
\hline \multirow[t]{3}{*}{ Inflammation } & No & 1 & Ref & & Ref & \\
\hline & Malarial Inflammation & & $3.8(0.56,25.70)$ & 0.174 & $1.8(0.44,7.36)$ & 0.415 \\
\hline & Non-malarial Inflammation & & $2.4(1.62,3.65)$ & $<0.001$ & $1.3(0.90,1.94)$ & 0.157 \\
\hline \multirow[t]{3}{*}{ Sickle cell (HBB genotype) } & AA & 1 & Ref & & Ref & \\
\hline & AS & & $1.00(0.59,1.55)$ & 0.853 & $1.6(1.03,2.35)$ & 0.035 \\
\hline & SS & & $1.2(0.10,13.54)$ & 0.904 & $16.6(3.56,77.04)$ & $<0.001$ \\
\hline \multicolumn{7}{|l|}{ Children under 6 month (2) } \\
\hline \multirow[t]{2}{*}{ Age } & Continuous variable & 1 & - & - & $1.3(1.02,1.57)$ & 0.031 \\
\hline & Normal & 1 & - & - & Ref & \\
\hline \multirow[t]{2}{*}{ Zinc } & Deficiency & & - & - & $1.1(0.20,5.85)$ & 0.927 \\
\hline & Overload & & - & - & $0.3(0.12,0.73)$ & 0.008 \\
\hline \multicolumn{7}{|l|}{ Children 6 to 23 months (3) } \\
\hline \multirow[t]{2}{*}{ Gender } & Female & 1 & & & & \\
\hline & Male & & $2.1(1.34,3.27)$ & 0.001 & $1.3(0.78,2.10)$ & 0.321 \\
\hline \multirow[t]{2}{*}{ Continued breastfeeding } & No & 1 & & & & \\
\hline & Yes & & $1.9(1.11,3.13)$ & 0.019 & $1.6(0.92,2.90)$ & 0.095 \\
\hline \multirow[t]{3}{*}{ Zinc } & Normal & 1 & & & & \\
\hline & Deficiency & & $1.4(0.42,4.48)$ & 0.604 & $4.4(1.55,12.28)$ & 0.005 \\
\hline & Overload & & $0.8(0.44,1.30)$ & 0.307 & $0.7(0.35,1.27)$ & 0.221 \\
\hline \multirow[t]{3}{*}{ Inflammation } & No & 1 & & & & \\
\hline & Malarial Inflammation & & $2.3(0.43,11.95)$ & 0.331 & $9.1(2.34,35.71)$ & 0.001 \\
\hline & Non-malarial Inflammation & & $2.2(1.42,3.47)$ & $<0.001$ & $1.5(0.90,2.48)$ & 0.119 \\
\hline \multicolumn{7}{|l|}{ Children 24 to 36 months (4) } \\
\hline Age & Continuous variable & 1 & $0.9(0.77,0.98)$ & 0.020 & $1.0(0.955,1.13)$ & 0.408 \\
\hline \multirow[t]{3}{*}{ Zinc } & Normal & 1 & & & & \\
\hline & Deficiency & & $1.4(0.38,5.28)$ & 0.609 & $3.6(1.41,9.09)$ & 0.007 \\
\hline & Overload & & $1.0(0.26,4.14)$ & 0.960 & $0.7(0.23,2.35)$ & 0.605 \\
\hline Stunting & Normal & 1 & & & & \\
\hline & Moderate to severe & & $2.6(1.09,6.20)$ & 0.031 & $1.2(0.60,2.23)$ & 0.675 \\
\hline Inflammation & No & & & & & \\
\hline & Malarial Inflammation & 1 & $18.2(3.55,92.76)$ & $<0.001$ & $2.3(0.54,9.94)$ & 0.262 \\
\hline & Non-malarial Inflammation & & $4.0(1.45,11.01)$ & 0.007 & $0.4(0.21,0.90)$ & 0.024 \\
\hline
\end{tabular}

Only variables with a significance level of $10 \%(p<0.10)$ were included as independent variables in a multivariate multinomial model [1]. Variables excluded from the model $(p>0.05)$ : educational level of the caregiver, breeding or hunting animals, main source of drinking and bath water and being infected with at least one intestinal or urogenital parasite. Model adjustment: Pearson: $\mathrm{X} 2(170)=162.9, p=0.638$; Deviance: $\mathrm{X} 2(170)=169.9, p=0.488$; R2 Nagelkerke $=0.208$ [2]. Variables excluded from the model $(p>0.05)$ : Inflammation (Non-malarial inflammation). Model adjustment: Pearson: $\mathrm{X} 2(22)=43.1, p=0.500 ;$ Deviance: $\mathrm{X} 2(22)=48.6, p=0.100 ; \mathrm{R} 2 \mathrm{Nagelkerke}=13.5 \%$ [3]. Variables excluded from the model $(p>0.05)$ : $\mathrm{N}^{\circ}$ of children, Minimum Dietary Diversity (Non-continued breastfeed), main water drinking source, $\mathrm{n}^{\circ}$ of children $<5$ years, having at least one intestinal/urogenital parasite, sickle cell, $P$. falciparum. Model adjustment: Pearson: $X 2(40)=27.3, p=0.938 ;$ Deviance: $X 2(40)=31.0, p=0.845 ; \mathrm{R} 2$ Nagelkerke $=13.0 \%$ [4]. Variables excluded from the model $(p>0.05)$ : Number of residents, latrine ownership, $P$. falciparum, Food frequency. Model adjustment: Pearson: $\mathrm{X} 2(176)=170.5, p=0.604$; Deviance: $\mathrm{X} 2(176)=167.0, p=0.675 ; \mathrm{R} 2$ Nagelkerke $=20.3 \%$ 
having inflammation and only zinc deficiency and malarial inflammation stood significantly associated with NonIDA (see Table 3). In the older age category, IDA was found to be associated age, stunting and inflammation, while children diagnosed with Non-IDA were more likely to have zinc deficiency, and inflammation without malaria.

\section{Discussion}

\section{Prevalence of anaemia}

In the present study, conducted in the Dande municipality in 2015, the prevalence of anaemia among under 5year-old children was $44.4 \%$, lower than previously reported for the Dande municipality (57\%) [13]. We found that prevalence's were higher in children aged between 6-to-23 months (52\%), comparatively to under 6 months and 24-to-36 months children (respectively 52, 36 and 35\%). This is in accordance with children development $[44,45]$. However, its contrary to national estimates reporting higher prevalence's in younger children (between 6-to- 11 months, specially in 6-8 months children (reaching near 83\%)), and worldwide estimates (reporting higher prevalence in 1-to-12 month children) $[1,11]$. Nevertheless, the low density of under 6-month children should be taken into consideration.

The prevalence of IDA was also lower than expected (46\% of all anaemic children), as it is generally assumed that half of the anaemia cases are due to iron deficiency $[4,46,47]$. This lower contribution of micronutrient deficiencies to the total anaemia, was also previously described in the South Sub-Saharan Africa (while an higher contribution of infections and sickle cell was estimated for the central and Western areas) $[1,4,48]$. Here, our results suggest that within this context, beside the factors compromising iron imbalance (such as blood loss, inadequate iron ingestion or compromised iron absorption), other associated factors may be of greater importance [4, 47]. Thus, this study add a modest contribution to the comprehensive work published by Kassebaum et al, by describing the factors specifically associated with the occurrence of IDA and Non-IDA in pre-school children of northern Angola, further discussed below [1, 4].

\section{Factors associated with IDA and non-IDA}

Here, adjusted multiple multinomial regression models showed that the relevant factors associated with the occurrence of IDA within this setting were (a) age (6-to-23month children had 7.4 times more odds of having IDA than under 6 months children), (b) gender (males had 1.96 more odds than females) and (c) inflammation (particularly non-malarial inflammation). In the same models, the occurrence of Non-IDA was also associated with the children's age, besides zinc deficiency and overload, $P$. falciparum infection and sickle cell trait/anaemia (see Fig. 1).

The occurrence of total anaemia (in 2-15 years old children) have already been previously associated with gender, age, $P$. falciparum and $S$. haematobium infection in 2-15 years old children from this setting in 2010 [13]. Extending that knowledge, the present study documents that children's age associates differently with IDA and Non-IDA and that gender possibly influence more the occurrence of IDA. Those differential associations may be related to different underlying factors of IDA and Non-IDA within those groups [49]. For instance, the increased risk of IDA observed in the 6-to-23-month group may be potentially related with the higher iron requirements in children within these age group, as also reported in other African studies [48]. Regarding the differentiated influence of gender, it is suggested that males may have lower iron stores, and higher rates of iron deficiency than female infants $[50,51]$.

Our study also corroborates the relevant association between $P$. falciparum and anaemia, particularizing that in our study area is mainly associated with Non-IDA. Malarial anaemia (mainly severe anaemia) may result from acute and chronic haemolysis and/or systemic inflammation (that impair erythropoiesis), and considering that pre-existent iron deficiency is reported to worsen this condition, it would be expected that P. falciparum infections were also associated IDA [40, 48, 52-54]. Here, the higher frequency of malaria cases in the NonIDA children could have contributed to the statistical significance observed and explain the higher analytical robustness. However, P. falciparum could also be less prevalent in the IDA group due to the lower availability of iron for parasite multiplication [55].

Besides the confirmation and knowledge extension of previously published results for this geographic area, we also document the relevance of infection-related inflammation as important factor for the occurrence of IDA anaemia, apart from malaria. Regarding the non-malarial parasites studied here, the literature mentions an "immune activation" effect mainly for Schistosome and Giardia infections [56-59]. Nevertheless, it should be considered that other infections, not studied here, could also be contributing to the occurrence of infectionrelated inflammation (such as HIV, tuberculosis and other tropical enteropathies), and consequently to anaemia $[16,52,60]$.

One of the more important relevant evidence documented in this study is the association of Non-IDA with zinc levels, namely zinc deficiency associated with increasing IDA and zinc overload having a protective effect, In one hand, during zinc deficiency, the withdraw of zinc from tissues may occur, leading to increased hepcidin synthesis, which will reduce iron uptake, affecting 


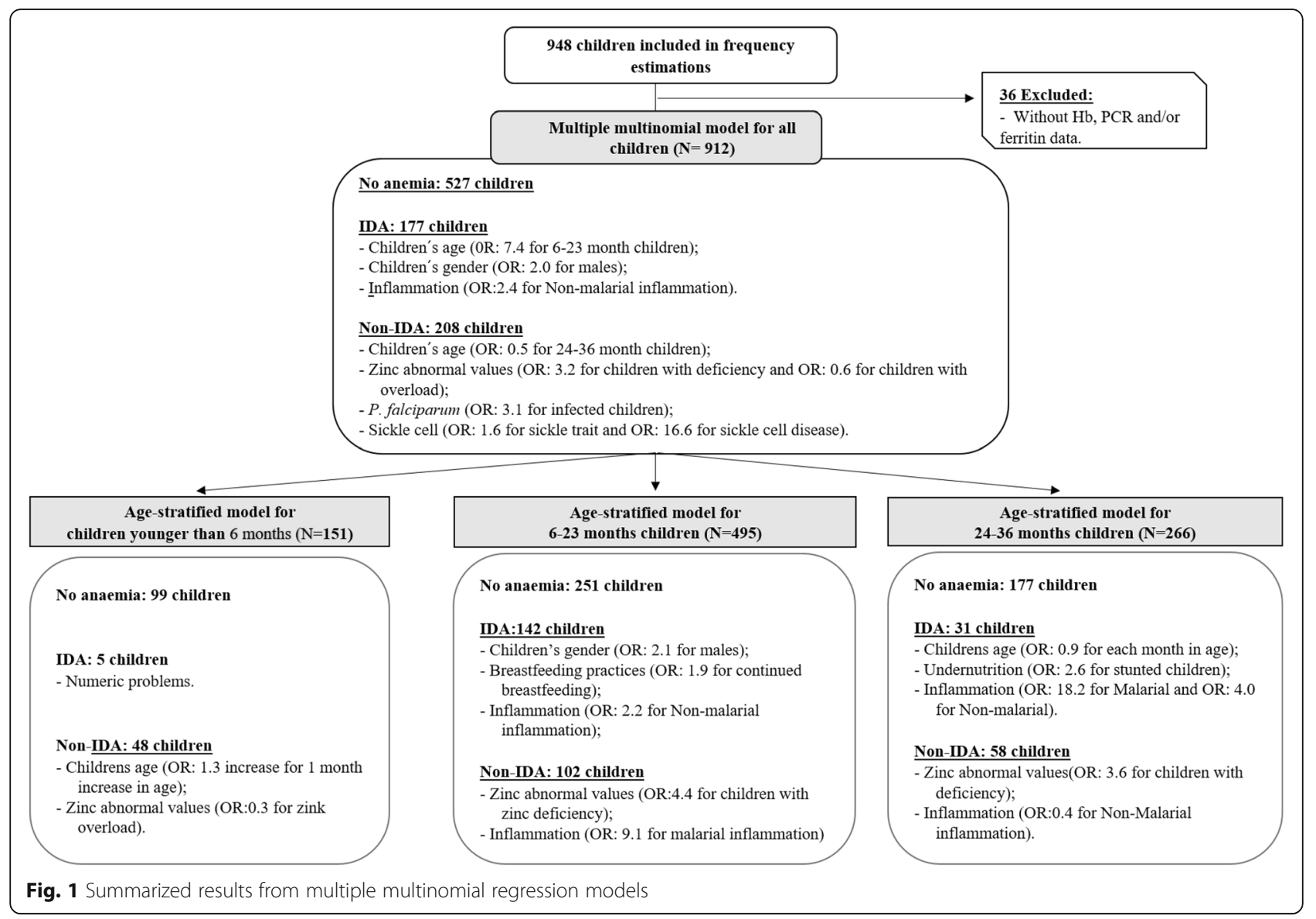

erythropoiesis, even in the presence of adequate iron stores $[61,62]$. On the other hand, while zinc deficiency was reported to lead to immune dysfunctions (and consequently worse responses towards infections and increased infection-related anaemia), increased zinc levels may protect against enteric bacterial pathogens, possibly acting as an inhibitor of pathogen's virulence and preventing micronutrients malabsorption [63-65]. Thus, we hypothesized that zinc deficiency may be associating with iron status, inflammation and/or infections in the causality to Non-IDA. This kind of nutritional immunity could help explaining the protective (possibly confounded) effect of being infected with at least one intestinal/urogenital parasite observed on children with IDA in crude models, considering that the opposite association was expected $[64,66]$.

Lastly, the association between Non-IDA and sickle cell anaemia was not surprising, considering that this hereditary disease has been long known to present low average haemoglobin values $(7-8 \mathrm{~g} / \mathrm{dL})[67,68]$. Newborn infants with sickle cell anaemia are reported to be healthy due to predominant production of fetal haemoglobin while in the uterus and neonatal period, but anaemia and haemolysis are evidenced after 4-6 months of age [68]. Also, the carriers of sickle cell trait (AS) were suggested to have a relative survival advantage over people with normal haemoglobin in regions where malaria is endemic, but this is neither absolute protection nor invulnerability to the disease $[68,69]$.

\section{Age-related factors associated with IDA and non-IDA}

In general, the proportion of anemia attributable to the nutritional, infectious and genetic causes discussed above may vary according to several physiologic and biologic aspects, as also according to the regional prevalence of anaemia etiologies and their underlying causes. Kassebaum et al., 2014, estimated that the anaemia cause-specific profile for children aging 0-to-27 days was composed mainly by IDA, hemoglobinopathies and infections (other than malaria, hookworms and schistosomiasis) [1, 4]. In children aging between 28 and 364 days, the contribution of IDA become less relevant, the impact of hemoglobinopathies is sustained and the contribution of Neglected Tropical Diseases and malaria become more relevant, shift that become more evident in 1 
to 4 years old children [1]. The age-specific factors associated with IDA and Non-IDA are presented in Fig. 1.

\section{Under 6 months children}

Besides having age (monthly) variations within the under six-month children in the occurrence of Non-IDA, the statistically significant association between Non-IDA and zinc overload, discussed above, was sustained in this age group, suggesting that the protective effect of high levels of zinc may begin at early ages. Unfortunately, numeric problems prevented us from determining IDA associated factors in this age group.

\section{6-to-23 months children}

Here, children who had already been introduced to complementary food and were still breastfeeding, were more susceptible of having IDA than children that were in exclusive complementary feeding. Previously, Pasricha et al 2011 reported that Indian children that were continued breastfeed were more likely to receive poorer complementary fed, also belonging to highly food insecure households, and poorer micronutrient status [70] Despite that the breast milk is an important source of iron, its intake and absorption may be insufficient to meet the amount required for growth and complementary foods are expected to balance that [71, 72].

Also, our results regarding inflammation suggest that in this age group, non-malarial infections may be contributing more to IDA, while $P$. falciparum malaria may be contributing mainly to Non-IDA, both possibly through inflammation. Considering also the effect of zinc deficiency, inflammation and malaria on the occurrence of Non-IDA, the hypothesis of zinc playing an important role in the nutritional immunity of those children may become more plausible.

\section{4-to-36 months children}

At this age group, children with either non-malarial or malarial inflammation had more chances of having IDA, comparatively to children without inflammation. These observations may be in accordance with reports describing that the decreasing impact of IDA, and increasing contribution of malaria and Neglected Tropical Diseases (NTD) to the occurrence of anaemia, may be more relevant 1 to 4 years old children, when hookworm and schistosomiasis become important [4]. Besides this recurrent association with infections and/or inflammation, stunted children were observed to have more chances of having IDA, while children with zinc deficiency were more likely to have Non-IDA. Regarding stunting, it should be noted that nutritional anaemias, particularly IDA, are directly linked to micronutrient deficiencies (mainly iron deficiency), and possibly to the long periods of nutritional restriction that leads to stunting $[15,40]$.

\section{Study strengths and limitations}

Although some measures were applied to reduce bias and confounding, this study has associated limitations that should be considered when interpreting our results. Mainly, the small population sample could have limited the estimation of associations with diseases with low frequency, the occurrence of differential missing (which influenced the final denominators of composite variables) and the convenient sampling design of this study doesn't allow for result extrapolation to the Dande municipality. Also, this cross-sectional design may misrepresent close relations between predictors and intermediary steps in the causal pathway to anaemia. Furthermore, the lack of data of other relevant conditions/diseases that could lead to anaemia, such as other relevant infections (HIV), other enzymopathies (such as Pyruvate Kinase Deficiency), and other types of anaemia, such as acquired and hereditary aplastic anaemias, limit the complete comprehension of the problem. Also, some methodological constrains may have influenced the frequency estimation of intestinal and urogenital parasites studied here. Namely, impossibility to perform Kato Katz in diarrheal samples (limiting the diagnosis of helminths) and single sample diagnosis. For instance, it was reported that the KatoKats sensitivity to diagnose hookworms using only one stool sample, was $65.2 \%$ [73].

\section{Conclusions}

This study has observed that the main variables associated with IDA within this geographic setting are age, sex and inflammation, while the factors associated with nonIDA were age, zinc deficiency or overload, $P$. falciparum infection and sickle cell anaemia. While most of those associations were commonly reported for the occurrence of total anaemia in Africa, here they were associated in specific with IDA and/or Non-IDA. Additionally, the associations with inflammation, zinc deficiency and infections could be suggesting the occurrence of nutritional immunity in the pathway to anaemia within these Angolan children, calling for additional research. In age groups, zinc overload was suggested to protect under 6 months children from Non-IDA, while continued breastfeeding was associated with increased IDA prevalence in 6-to-23 months children, and stunting was suggested to increase the odds of IDA in 24-to-36 month children. This site-specific profile can inform the planification of preventive and corrective actions/programs.

\section{Abbreviations}

BMI: Body Mass Index; CISA: Health Research Center of Angola (Translated); CRP: C-reactive protein; G6PD: Glucose-6-phosfate dehydrogenase; HAZ: Height-for-age; Hb: Haemoglobin; HDSS: Health and Demographic Surveillance System; IDA: Iron deficiency anaemia; IYCF: Infant and Young Child Feeding; MDD: Minimum Dietary Diversity; Non-IDA: Non-iron deficiency anaemia; NTD: Neglected Tropical Diseases; PCR: Polymerase chain 
reaction; WASH: Water sanitation and hygiene; WHO: World Health Organization; WAZ: Weight-for-age; WHZ: Weight-for-height

\section{Acknowledgements}

The authors acknowledge the support from the Angola's National Malaria Control and Neglected Tropical Diseases Control programs, specially of the coordinators and Caxito's local personnel in 2015. Also, we which to thank the directors from the Bengo's General Hospital, the Provincial Health direction and Paediatric Hospital David Bernardino. Furthermore, we thank the critical scientific contributions of Diogo Costa, Pedro Gil and José Figueiredo and the technical support from the department of Human Genetics, National Health Institute Dr. Ricardo Jorge in Portugal. Finally, we acknowledge the field, lab and nurse technicians and the head supervisors (specially Inês Deus, Célia Negrão and Isabel Clemente) of this project and also the local nurses, traditional and administrative authorities, and the population from Roldinho, Paranhos, Caboxa, Riceno, Sassa povoação, Porto Quipiri and Boa Esperança.

\section{Authors' contributions}

CF - conceptualized the research question and participated in the design (mainly the laboratory operational procedures for parasitological, biochemical, and molecular analysis) and implementing the study (mainly coordinating and supervising the recruitment of participants in the field). Also, carried out the molecular analysis, performed the statistical analysis, drafted the initial manuscript, and revised the subsequent versions. AS - have adapted and structured the questionnaire, coordinated and supervised data collection in the field and critically reviewed the manuscript. $J$ - have designed the operational procedure for molecular analysis, provided technical support, and critically reviewed the manuscript. HB - helped conceptualizing the research question, critically oriented and supervised the initial statistical analysis and critically reviewed the manuscript. MB - helped conceptualizing the research question, participated in the overall study design and critically reviewed the manuscript. All authors approved the last version of the manuscript to be submitted and are responsible for this work.

\section{Funding}

This investigation received financial support from TDR, The Special Programme for Research and Training in Tropical diseases, co-sponsored by UNICEF, UNDP, the World Bank and WHO, the Calouste Gulbenkian Foundation, British Petroleum and from the Banco de Fomento Angola. Financial funders or material/facilities supporters had no role in the design of the study, collection of samples, analysis or interpretation of results and neither in the writing of the manuscript.

\section{Availability of data and materials}

Data supporting the results can be made available upon request.

\section{Ethics approval and consent to participate}

This study was approved by the Ethical Committee of the Ministry of Health of the Angola Republic. Children's caregivers (mainly the children's mothers) have signed an informed consent, after an information sheet was explained and delivered to them. Hospital-based and home-based consultations were held for the treatment of intestinal and urogenital parasites. Children with sickle cell were also followed in specific consultations. All the diagnostic and therapeutic resources used were provided free of charge.

\section{Consent for publication}

Not applicable.

\section{Competing interests}

The authors have no competing interests to declare.

\section{Author details}

${ }^{1}$ Health Research Center of Angola (CISA, translated), Caxito, Angola. ${ }^{2}$ Instituto de Saúde Pública da Universidade do Porto, Porto, Portugal. ${ }^{3}$ Departamento de Genetica Humana, Instituto nacional de Saúde Dr. Ricardo Jorge, Lisboa, Portugal. ${ }^{4}$ BiolSI, Faculdade de Ciências, Universidade de Lisboa, Lisboa, Portugal. ${ }^{5}$ Health and Technology Research Center, Escola Superior de Tecnologia da Saúde de Lisboa, Instituto Politécnico de Lisboa, Lisboa, Portugal.
Received: 30 October 2019 Accepted: 1 June 2020

Published online: 17 June 2020

\section{References}

1. Kassebaum NJ, Jasrasaria R, Naghavi M, Wulf SK, Johns N, Lozano R, et al. A systematic analysis of global anemia burden from 1990 to 2010. Blood. 2014;123(5):615-24.

2. Stevens GA, Finucane MM, De-Regil LM, Paciorek CJ, Flaxman SR, Branca F, et al. Global, regional, and national trends in haemoglobin concentration and prevalence of total and severe anaemia in children and pregnant and non-pregnant women for 1995-2011: a systematic analysis of populationrepresentative data. Lancet Glob Health. 2013;1(1):e16-25.

3. Ramakrishnan U. Nutritional anemias. USA: CRC Press; 2001.

4. Kassebaum NJ, Collaborators GBDA. The global burden of anemia. Hematol Oncol Clin North Am. 2016;30(2):247-308.

5. WHO. Worldwide prevalence of anaemia 1993-2005. WHO Global database on anaemia. Geneva: World Health Organization; 2008.

6. Pasricha SR. Anemia: a comprehensive global estimate. Blood. 2014; 123(5):611-2.

7. DeMaeyer $\mathrm{E}$, Adiels-Tegman M. The prevalence of anaemia in the world. World Health Stat Q. 1985;38(3):302-16.

8. McLean E, Cogswell M, Egli I, Wojdyla D, de Benoist B. Worldwide prevalence of anaemia, WHO vitamin and mineral nutrition information system, 1993-2005. Public Health Nutr. 2009;12(4):444-54.

9. Balarajan Y, Ramakrishnan U, Ozaltin E, Shankar AH, Subramanian SV. Anaemia in low-income and middle-income countries. Lancet. 2011; 378(9809):2123-35.

10. Ramakrishnan U. Nutritional Anemias - CRC series in modern nutrition. Boca Raton: CRC Press LLC; 2001.

11. INE M, MPDT. Inquérito de Indicadores Múltiplos e de Saúde (IIMS) 20152016, Luanda - Angola. Principais resultados. Maryland: Instituto Nacional de Estatística (INE), Ministério da Saúde (MINSA), Ministério do Planeamento e do Desenvolvimento Territorial (MPDT); 2017.

12. Oliveira D, Ferreira FS, Atouguia J, Fortes F, Guerra A, Centeno-Lima S. Infection by intestinal parasites, stunting and anemia in school-aged children from southern Angola. PLoS One. 2015;10(9):e0137327.

13. Sousa-Figueiredo JC, Gamboa D, Pedro JM, Fancony C, Langa AJ, Magalhaes RJ, et al. Epidemiology of malaria, schistosomiasis, geohelminths, anemia and malnutrition in the context of a demographic surveillance system in northern Angola. PLoS One. 2012;7(4):e33189.

14. Soares Magalhaes RJ, Langa A, Pedro JM, Sousa-Figueiredo JC, Clements AC, Vaz NS. Role of malnutrition and parasite infections in the spatial variation in children's anaemia risk in northern Angola. Geospat Health. 2013;7(2): 341-54.

15. Pasricha SR, Vijaykumar V, Prashanth NS, Sudarshan H, Biggs BA, Black J, et al. A community based field research project investigating anaemia amongst young children living in rural Karnataka, India: a cross sectional study. BMC Public Health. 2009;9:59.

16. Pullan $\mathrm{R}$, Brooker $\mathrm{S}$. The health impact of polyparasitism in humans: are we under-estimating the burden of parasitic diseases? Parasitology. 2008;135(7): 783-94.

17. Pasricha SR, Drakesmith H, Black J, Hipgrave D, Biggs BA. Control of iron deficiency anemia in low- and middle-income countries. Blood. 2013; 121(14):2607-17.

18. Clark MA, Goheen MM, Cerami C. Influence of host iron status on plasmodium falciparum infection. Front Pharmacol. 2014:5:84

19. Sazawal S, Black RE, Ramsan M, Chwaya HM, Stoltzfus RJ, Dutta A, et al. Effects of routine prophylactic supplementation with iron and folic acid on admission to hospital and mortality in preschool children in a high malaria transmission setting: community-based, randomised, placebo-controlled trial. Lancet. 2006;367(9505):133-43.

20. Rees DC, Williams TN, Gladwin MT. Sickle-cell disease. Lancet. 2010; 376(9757):2018-31.

21. Eziefula AC, Pett H, Grignard L, Opus S, Kiggundu M, Kamya MR, et al. Glucose-6-phosphate dehydrogenase status and risk of hemolysis in plasmodium falciparum-infected African children receiving single-dose primaquine. Antimicrob Agents Chemother. 2014;58(8):4971-3.

22. Rosario EVN, Costa D, Francisco D, Brito M. HDSS profile: the Dande Health and Demographic Surveillance System (Dande HDSS, Angola). Int J Epidemiol. 2017:46:1094. 
23. Costa J, Rosário E, Langa A, António G, Bendriss A, Vaz-Nery S. Setting up a demographic surveillance system in the Dande municipality, Angola. Afr Popul Stud. 2012;26:2.

24. Rosario EV, Costa D, Timoteo L, Rodrigues AA, Varanda J, Nery SV, et al. Main causes of death in Dande, Angola: results from verbal autopsies of deaths occurring during 2009-2012. BMC Public Health. 2016;16:719.

25. Gasparinho C, Mirante MC, Centeno-Lima S, Istrate C, Mayer AC, Tavira L, et al. Etiology of diarrhea in children younger than 5 years attending the Bengo general hospital in Angola. Pediatr Infect Dis J. 2016;35(2):e28-34.

26. Fancony $\mathrm{C}$, Brito M, Gil JP. Plasmodium falciparum drug resistance in Angola. Malar J. 2016;15:74.

27. Fancony C, Gamboa D, Sebastiao Y, Hallett R, Sutherland C, SousaFigueiredo JC, et al. Various pfcrt and pfmdr1 genotypes of plasmodium falciparum cocirculate with P. malariae, P. ovale spp., and P. vivax in northern Angola. Antimicrob Agents Chemother. 2012;56(10):5271-7.

28. Soares Magalhaes RJ, Fancony C, Gamboa D, Langa AJ, Sousa-Figueiredo JC, Clements AC, et al. Extending helminth control beyond STH and schistosomiasis: the case of human hymenolepiasis. PLoS Negl Trop Dis. 2013;7(10):e2321.

29. ProPAN. ProPAN : process for the promotion of child feeding. software user's guide version 2.0. Washington: Pan American Health Organization, United Nations Children's Fund; 2013.

30. WHO. Indicators for assessing infant and young child feeding practices part 2: measurement. Geneva: WHO, USAID, AED, FANTA.2, UCDAVIS, International Food Policy Research Institute, UNICEF; 2010.

31. WHO. Indicators for assessing infant and young child feeding practices: conclusions of a consensus meeting held 6-8 November 2007 in Washington D.C., USA. Geneva: World Health Organization; 2007.

32. WHO. Training course on child growth assessment: who child growth standards. Geneva: World Health Organization; 2008.

33. WHO. WHO guidelines on drawing blood: best practices in phlebotomy. Genva: World Health Organization; 2010.

34. WHO. Basic laboratory methods in medical parasitology. Geneva: WHO; 1991.

35. Mendoza NM, Cucunuba ZM, Aponte S, Gonzalez NE, Bernal SD. Field evaluation for diagnostic accuracy of the rapid test SD bioline malaria antigen Pf/Pv(R) in Colombia. Biomedica. 2013;33(4):587-97.

36. Katz N, Chaves A, Pellegrino J. A simple device for quantitative stool thicksmear technique in Schistosomiasis mansoni. Rev Inst Med Trop Sao Paulo. 1972;14(6):397-400.

37. Brito MTC, Santos B, Veiga L. Glucose-6-phosphate dehydrogenase deficiency in children from 0 to 14 years hospitalized at the pediatric hospital David Bernardino, Luanda, Angola. Pharmacogenomics. 2014;5:2.

38. Waterfall CM, Cobb BD. Single tube genotyping of sickle cell anaemia using PCR-based SNP analysis. Nucleic Acids Res. 2001;29(23):E119.

39. WHO. Haemoglobin concentrations for the diagnosis of anaemia and assessment of severity. Geneva: World Health Organization; 2011.

40. WHO. Nutritional anaemias: tools for effective prevention and control. Geneva: World Health Organization; 2017.

41. Garcia-Casal MN, Pena-Rosas JP, Pasricha SR. Rethinking ferritin cutoffs for iron deficiency and overload. Lancet Haematol. 2014;1(3):e92-4.

42. Trumbo P, Yates AA, Schlicker S, Poos M. Dietary reference intakes: vitamin A, vitamin $\mathrm{K}$, arsenic, boron, chromium, copper, iodine, iron, manganese, molybdenum, nickel, silicon, vanadium, and zinc. J Am Diet Assoc. 2001; 101(3):294-301.

43. WFP C. A manual: measuring and interpreting malnutrition and mortality. 2005.

44. Subramaniam G, Girish M. Iron deficiency anemia in children. Indian J Pediatr. 2015;82(6):558-64.

45. Ahluwalia N. Nutrition Monitoring of Children Aged Birth to $24 \mathrm{Mo}$ (B-24): Data Collection and Findings from the NHANES. Adv Nutr. 2020;11(1):11327. https://doi.org/10.1093/advances/nmz077.

46. WHO. Iron deficiency anaemia assessment, prevention and control A guide for programme managers. Geneva: World Health Organization Press; 2001.

47. DeLoughery TG. Iron deficiency anemia. Med Clin North Am. 2017;101(2): 319-32.

48. Barffour MA, Schulze KJ, Kalungwana N, Moss WJ, West KP Jr, Chileshe J, et al. Relative contributions of malaria, inflammation, and deficiencies of Iron and vitamin A to the burden of anemia during low and high malaria seasons in rural Zambian children. J Pediatr. 2019;213:74-81 e1.

49. Fançony $\mathrm{CL}$, Brito $\mathrm{M}$, Barros $\mathrm{H}$. Anemia in preschool children from Angola: a review of the evidence. Porto Biomed J. 2020;5(1):e60.
50. Ziegler EE, Nelson SE, Jeter JM. Iron stores of breastfed infants during the first year of life. Nutrients. 2014;6(5):2023-34.

51. Domellof M, Lonnerdal B, Dewey KG, Cohen RJ, Rivera LL, Hernell O. Sex differences in iron status during infancy. Pediatrics. 2002;110(3):545-52.

52. Foote EM, Sullivan KM, Ruth LJ, Oremo J, Sadumah I, Williams TN, et al. Determinants of anemia among preschool children in rural, western Kenya. Am J Trop Med Hyg. 2013;88(4):757-64.

53. Menendez C, Fleming AF, Alonso PL. Malaria-related anaemia. Parasitol Today. 2000;16(11):469-76.

54. Barreiro P, Tiziano G, Fano H, Yohannes T, Gosa A, Reyes F, et al. Malaria and severe anemia over eight years at Gambo rural hospital, southern Ethiopia. Pathog Glob Health. 2017;111(4):195-9.

55. Nussenblatt $\mathrm{V}$, Semba RD. Micronutrient malnutrition and the pathogenesis of malarial anemia. Acta Trop. 2002;82(3):321-37.

56. Stephenson LS, Latham MC, Ottesen EA. Malnutrition and parasitic helminth infections. Parasitology. 2000;121(Suppl):S23-38.

57. Friedman JF, Kanzaria HK, McGarvey ST. Human schistosomiasis and anemia: the relationship and potential mechanisms. Trends Parasitol. 2005;21(8):386-92.

58. Leenstra T, Coutinho HM, Acosta LP, Langdon GC, Su L, Olveda RM, et al. Schistosoma japonicum reinfection after praziquantel treatment causes anemia associated with inflammation. Infect Immun. 2006;74(11):6398-407.

59. Webster BH. Human infection with Giardia lamblia; an analysis of 32 cases. Am J Dig Dis. 1958;3(1):64-71.

60. Shaw JG, Friedman JF. Iron deficiency anemia: focus on infectious diseases in lesser developed countries. Anemia. 2011;2011:260380.

61. Knez M, Graham RD, Welch RM, Stangoulis JC. New perspectives on the regulation of iron absorption via cellular zinc concentrations in humans. Crit Rev Food Sci Nutr. 2017:57(10):2128-43.

62. Zhang AS, Enns CA. Iron homeostasis: recently identified proteins provide insight into novel control mechanisms. J Biol Chem. 2009;284(2):711-5.

63. Crane JK, Broome JE, Reddinger RM, Werth BB. Zinc protects against Shigatoxigenic Escherichia coli by acting on host tissues as well as on bacteria. BMC Microbiol. 2014;14:145.

64. Gammoh NZ, Rink L. Zinc in infection and inflammation. Nutrients. 2017; 9(6):624.

65. Eide DJ. Zinc transporters and the cellular trafficking of zinc. Biochim Biophys Acta. 2006;1763(7):711-22

66. Petney TN, Andrews RH. Multiparasite communities in animals and humans: frequency, structure and pathogenic significance. Int J Parasitol. 1998;28(3): 377-93.

67. Bender MA. Sickle Cell Disease. In: Adam MP, Ardinger HH, Pagon RA, et al., eds. GeneReviews ${ }^{\oplus}$. Seattle: University of Washington; 1993.

68. Bridges KRaP, H. A. Anemias and other red cell disordes. 1st ed; 2007. p. 384

69. do Sambo MR, Penha-Goncalves C, Trovoada MJ, Costa J, Lardoeyt R, Coutinho A. Quantitative trait locus analysis of parasite density reveals that $\mathrm{HbS}$ gene carriage protects severe malaria patients against Plasmodium falciparum hyperparasitaemia. Malar J. 2015;14:393.

70. Pasricha SR, Shet AS, Black JF, Sudarshan H, Prashanth NS, Biggs BA. Vitamin B-12, folate, iron, and vitamin A concentrations in rural Indian children are associated with continued breastfeeding, complementary diet, and maternal nutrition. Am J Clin Nutr. 2011;94(5):1358-70.

71. Griffin IJ, Abrams SA. Iron and breastfeeding. Pediatr Clin N Am. 2001;48(2): 401-13.

72. Meinzen-Derr JK, Guerrero ML, Altaye M, Ortega-Gallegos H, Ruiz-Palacios GM, Morrow AL. Risk of infant anemia is associated with exclusive breast-feeding and maternal anemia in a Mexican cohort. J Nutr. 2006;136(2):452-8.

73. Tarafder MR, Carabin H, Joseph L, Balolong E Jr, Olveda R, McGarvey ST. Estimating the sensitivity and specificity of Kato-Katz stool examination technique for detection of hookworms, Ascaris lumbricoides and Trichuris trichiura infections in humans in the absence of a 'gold standard'. Int J Parasitol. 2010;40(4):399-404.

\section{Publisher's Note}

Springer Nature remains neutral with regard to jurisdictional claims in published maps and institutional affiliations. 